\title{
Conceitos Winnicottianos integrados na clínica ampliada: um olhar sobre o tratamento do transtorno mental grave na infância
}

\section{Winnicott's concept incorporated in enlarged clinic: a look at the treatment of childhood severe mental disorder}

\author{
Nelcí Regina Angnes* \\ Universidade Federal de Santa Maria - UFSM, Santa Maria, Rio Grande do Sul, \\ Brasil
}

\section{Caroline Matos Romio**}

Universidade Federal de Santa Maria - UFSM, Santa Maria, Rio Grande do Sul, Brasil

\section{Gabriela Zuchetto***}

Universidade Federal de Santa Maria - UFSM, Santa Maria, Rio Grande do Sul, Brasil

\section{Hericka Zogbi J orge Dias****}

Centro Universitário Ritter dos Reis, UNIRITTER, Porto Alegre, Rio Grande do Sul, Brasil

\begin{abstract}
RESUMO
A presente elaboração teórica surge do interesse de se entremear conceitos presentes na psicologia do desenvolvimento emocional com as diretrizes da assistência em saúde, na atenção à saúde mental. A análise conceitual se propõe a articular os referenciais elaborados por D. W. Winnicott com a cartilha do Ministério da Saúde sobre a Clínica Ampliada na atenção à saúde mental infantil. A relevância deste artigo consiste na necessidade de se pensar como a gestão em saúde pode tornar possível, no âmbito público, o atendimento do transtorno mental grave na infância a partir dos pressupostos trazidos por Winnicott, tais como integração, autonomia e o papel do ambiente no desenvolvimento emocional.
\end{abstract}

Palavras-chaves: Clínica Ampliada, Transtorno Mental Grave na Infância, Winnicott, Promoção de Saúde.

\section{ABSTRACT}

This theoretical elaboration stems from an interest to interweave concepts in emotional developmental psychology with the guidelines of health care, attention to mental health. The conceptual analysis was intended to combine the references used by Winnicott with to the booklet of the Health Ministry on the enlarged clinic in mental health care for children. The relevance of this article is based on the need to consider how health management can make possible, in public services, the care of children with severe mental 
disorders, based on the premises carried by Winnicott like integration, autonomy and the role of ambient on emotional development.

Keywords: Enlarged clinic, Childhood Severe Mental Disorders, Winnicott, Health Promotion.

\section{Introdução}

A Clínica Ampliada é uma das diretrizes estabelecidas pelo Sistema Único de Saúde (SUS) e tem como finalidade efetivar os princípios deste, tais como resolubilidade, descentralização da saúde e participação dos cidadãos nesse processo. Esse modelo de clínica se propõe, a partir de uma responsabilidade com o sujeito em tratamento, a promover atenção plena e intersetorial, possibilitando a confluência entre as áreas de conhecimento profissional. Surge como uma ferramenta de conversação dos enfoques biomédico, social e psicológico, na tentativa de integrar os saberes e suas práticas. Ampliando o entendimento acerca da saúde e do sujeito em tratamento, que passa a ser visto para além de sua doença (MINISTÉRIO DA SAÚDE, 2004; 2009).

Cabe destacar que, no plano da saúde coletiva, ampliar os processos de promoção e prevenção de saúde implica em construir uma rede em que, comunidade, serviços, profissionais e gestores atuem de forma conjunta e participativa na construção de uma clínica compartilhada. Assim, as ações e práticas da Clínica Ampliada se compõem através de uma construção conjunta dos diagnósticos e projetos terapêuticos, com expansão da compreensão acerca do "objeto de trabalho" e a modificação dos instrumentos de trabalho, possibilitando ainda um maior suporte para os profissionais de saúde (MINISTÉRIO DA SAÚDE, 2004; 2009).

Com isso, segundo o Ministério da Saúde (2009), a Clínica Ampliada propõe o estabelecimento de uma rede onde os sujeitos, sejam eles usuários, trabalhadores ou gestores, estejam vinculados entre si e com o tratamento. Isso para que seja possível a garantia de atenção resolutiva e humanizada a todos. Assim, a Clínica Ampliada pretende abarcar as ações em saúde pública, tanto destinadas à atenção de transtornos físicos quanto psíquicos, apresentados na infância, adolescência ou idade adulta.

Por se tratar de uma ampla rede de gestão e atenção em saúde, surge a necessidade de se pensar a correlação dos preceitos preconizados pela Clínica Ampliada com as possibilidades de intervenção psíquica junto ao público infanto-juvenil com transtorno mental grave. Este público necessita de um olhar exclusivo, isso porque, de acordo com relatório da Organização Mundial da Saúde (2002), de 10 a $20 \%$ da população infantil sofre de algum tipo de doença mental ou sofrimento mental. Além do mais, conforme Couto 
(2008), este público demanda uma atenção especial que muitas vezes é negligenciado nas políticas de saúde pública. Isso porque os sofrimentos mentais presentes na infância podem prejudicar 0 desenvolvimento da criança e costumam estar associados à incidência de transtornos emocionais na vida adulta (ROBERTS, ATTKISSON E ROSENBLATT, 1998; FERRIOLLI, MARTURANO E PUNTEL, 2007). Além disso, na população infanto-juvenil com transtorno mental, devem ser levados em consideração os diferentes tipos de patologia e as estratégias de intervenção quando se pensa em promoção de saúde para esse público.

Nesse sentido, a oferta de práticas clínicas constituídas através da escuta e das relações permeadas por afeto se faz imprescindível. Estes aspectos são viabilizados pela proposta da Clínica Ampliada que, acrescenta ainda, a necessidade da construção do projeto terapêutico singular. Para tanto, é imprescindível que ocorram reuniões de equipe, que devem possibilitar a troca de informações entre profissionais e o planejamento conjunto do projeto terapêutico de usuários, para isso, é preciso uma gestão que possibilite a todos a oportunidade para falar (MINISTÉRIO DA SAÚDE, 2004; 2009).

\section{Desenvolvimento infantil na teoria de Winnicott}

D. W. Winnicott (2005), reconhecido teórico do desenvolvimento emocional humano no campo da psicologia, ressaltou a importância do ambiente como promotor de saúde e facilitador no processo do desenvolvimento emocional. Ainda, segundo o autor, todos os seres nascem com potencial inato para o desenvolvimento, mas para que esse ocorra é preciso que se estabeleçam condições ambientais favoráveis.

Em Winnicott (1983), o ambiente facilitador do processo maturacional tem como característica central a confiabilidade, e está ligado à dependência, entendida como absoluta no que concerne a relação inicial mãe-bebê. Nessa etapa do desenvolvimento é a confiabilidade ambiental que possibilita ao bebê a constituição da identidade, da diferenciação, possibilitando o estabelecimento dos sentidos de realidade e de existência. Posterior a essa etapa, segundo Winnicott (1983), ocorre o período da dependência relativa e por fim a independência, que será sempre relativa.

A dependência absoluta está relacionada ao início da vida e aos cuidados essenciais, é o momento no qual, o papel do mundo externo (composto pelos objetos externos e pelo ambiente) é mais decisivo. Nesse período, a criança não tem a capacidade de estar consciente dessa dependência e tem como ganho a possibilidade de um desenvolvimento saudável, sustentado por um ambiente que the 
permita as primeiras experiências rumo a um maior grau de autonomia.

Esse ambiente contará com a presença de uma pessoa (mãe ou cuidador) denominada de "mãe suficientemente boa", que é capaz de identificar-se com o bebê, satisfazer e se adaptar as necessidades dele de modo bom e adequado, fazendo com que ele seja capaz de ter uma breve experiência de onipotência e fantasias de autosatisfação e, gradativamente essa adaptação vai diminuindo segundo a crescente capacidade do bebê em tolerar os resultados da frustração (Winnicott, 1975). Em decorrência de uma série de sensações corporais dispersas e não integradas entre si, as quais se sucedem várias vezes, estas inscrevem 0 bebê no diferencial desprazer/prazer. Segundo Winnicott (1956/2000a), a repetição constante dessas experiências de satisfação, é que vão permitir a integração.

Portanto, no processo de integração, temos uma série permanente de impulsos que precisam ser satisfeitos e o holding materno/ambiental que permite a satisfação de forma menos traumática possível, fornecendo-Ihes significados, sentidos e contornos ao sem-sentido originário. Para o autor, caso o ambiente/mãe não seja capaz de amparar essa marcha à integração, a experiência das agonias impensáveis se posiciona, como uma reação às falhas ambientais no sentido de intrusões ou invasões sobre o despreparado bebê. Segundo Winnicott (1966/1994), a existência do bebê se coloca em termos de vida ou morte, já que sozinho não poderia levar adiante sua própria existência.Dessa forma, ocorrem agonias impensáveis, devido a ausência de recursos de linguagem para simbolizá-las, as quais são sentidas pelo bebê como ameaças de aniquilamento que o impactam no nível corporal.

Superados os perigos de aniquilamento e não integração do ego, o bebê chegará a um estágio de dependência relativa, em que a "mãe suficientemente boa", estará gradativamente se afastando dele, o que gera desconforto e ansiedade, no entanto, a necessidade dos cuidados da mãe já pode ser percebida. Quanto maior a riqueza de contato com o mundo tiver a criança - visto que, em um ambiente favorável, o mundo deve ser a todo o momento apresentado a elamaior será seu repertório de recursos que poderá lançar mão para suportar a ausência da mãe e tolerar sua ansiedade. O ganho mais significativo decorrente da fase de dependência relativa é a tomada de consciência, por parte do bebê, da sua dependência com relação à mãe (Winnicott, 1983).

Winnicott (1983) descreve o desenvolvimento humano em termos de graus de dependência do individuo com relação ao ambiente. Pode-se pensar essa linha de desenvolvimento como uma jornada rumo a um maior grau de autonomia e independência possível do sujeito, visto 
que não há possibilidades de uma autonomia absoluta, e sim de uma relação de interdependência com o social.

0 ambiente suficientemente bom falha em atender algumas necessidades da criança, em algum momento, de forma gradativa, após ter suprido todas as necessidades de satisfação, e essa falha é necessária para o ganho de autonomia dos indivíduos. No entanto, quando a mãe não consegue identificar-se e adaptar-se às necessidades do bebê, tem dificuldades em acolher os seus gestos de espontaneidade, em um estágio inicial da vida, essas falhas levam a consequências especificas no desenvolvimento da saúde mental.

Caso o ambiente falhe na provisão das necessidades básicas, as experiências iniciais, de alimentação, por exemplo, são sentidas como invasivas e a criança é levada a reagir à elas. Nesse caso, o sujeito em desenvolvimento vivencia uma não integração ou uma desintegração, vendo-se impossibilitado de atribuir significado, nomear e organizar as experiências de contato com o mundo externo e o seu próprio corpo (SANTOS, 1999).

\section{Transtorno grave na infância}

Para Winnicott (1983), todo indivíduo humano é dotado de uma tendência inata ao amadurecimento, e esse corresponde à capacidade humana de se integrar em uma unidade, ou seja, integrar-se numa unidade psique-soma, unindo os aspectos psicológicos com os corporais. I nata no sentido que tende a ocorrer com o tempo, de modo espontâneo, no entanto precisa de condições para acontecer, não é determinante. Desse amadurecimento irá depender a saúde emocional do sujeito, e através da constituição do indivíduo esse passará a ter um sentido de realidade e de existência, ao perceber-se diferenciado dos demais.

Desse modo, nos casos de adoecimento emocional na infância, ou fora dela, ocorre uma não-integração ou desintegração do eu. Com isso, o estabelecimento das relações objetais fracassa, o sujeito se relaciona com um mundo subjetivo particular ou falha em se relacionar com qualquer objeto externo. A onipotência é assegurada através de delírios. O paciente se retrai e fica fora de contato, passa a ter referências irreais (TOLEDO, 2008; WINNICOTT 1983).

Segundo Winnicott (1983), os transtornos graves estão associados a falhas no ambiente que não pode dar o suporte necessário a criança, nem se adaptar as demandas desta. Esse ambiente ao qual o autor se refere, pode estar representado por uma mãe que, igualmente desamparada, foi incapaz de possibilitar ao bebê a integração, personalização e desenvolvimento das relações objetais, metas colocadas pelo autor como fundamentais para se atingir 0 desenvolvimento emocional saudável. Diante disso, os transtornos 
mentais se formam na base de falhas da provisão ambiental e podem ser tratados, muitas vezes com êxito, por nova provisão ambiental.

Perante o exposto, é possível pensar que as diretrizes do modelo de Clínica Ampliada podem proporcionar para a criança/adolescente em sofrimento psíquico, no âmbito público, a reconstrução de um ambiente que seja capaz de propiciar condições de integração, desenvolvimento e saúde, através de um ambiente facilitador.

\section{A promoção da integração}

No que concerne a possibilidade de uma nova provisão ambiental, a Clínica Ampliada propõe uma forma de trabalhar de modo acolhedor, pensando o cuidado de modo integrado, em dimensões diferentes para que a integralidade da atenção em saúde seja alcançada de maneira mais completa. Essas dimensões são compostas tanto pela integralidade focalizada, que é o resultado do esforço e da união de diversos saberes de uma equipe multiprofissional, quanto a integralidade ampliada, que consiste na articulação de cada serviço de saúde a uma rede mais complexa, ou seja, a integralidade pensada no "macro", aqui entendido como as articulações, comunicações e circuitos estabelecidos entre serviços em todo o sistema de saúde (CAÇAPAVA, COLVERO e MARTINES, 2009a; CARVALHO e CECÍLIO, 2007).

Nos aspectos singulares do desenvolvimento, a ideia de sujeito integrado surge na obra de Winnicott (1975) como uma tendência do ser humano de integrar-se no espaço e tempo, desde que suas demandas sejam atendidas por um ambiente facilitador. Essa tendência é o que possibilita ao sujeito perceber-se enquanto unidade, utilizando o pronome pessoal "eu" (TOLEDO, 2008b).

Porém, as falhas permanentes do ambiente, que fazem com que o bebê perceba aquele como não confiável, ou ainda excessos do ambiente que nunca falta, e com isso sufoca os movimentos de independência e espontaneidade do bebê, podem ocasionar comprometimentos no processo de amadurecimento. Nesse sentido, a proposta de trabalho da Clínica Ampliada, prevê a promoção da integração em sujeitos não integrados através da construção e manutenção de um ambiente relacional favorável. Esse ambiente deve ser confiável e seguro, permitindo que o sujeito se sinta amparado, em suas demandas, acolhido em suas singularidades e motivado através de uma relação segura, a se movimentar rumo a um maior grau de autonomia, podendo sempre contar com o apoio desse ambiente.

A partir das proposições de Winnicott e dos norteadores da Clínica Ampliada, compreendemos que este dispositivo seja o principal modelo de atenção com vistas à integração do sujeito. O autor, em 
suas elaborações teóricas sobre o papel do ambiente no desenvolvimento emocional, torna-se atual quando tais elaborações podem ser reconhecidas na base de um dispositivo de atenção em saúde.

No entanto, há desafios acerca da promoção da integralidade, tanto focalizada, quanto ampliada, dentro do modelo da Clínica Ampliada. Esses desafios se dão na articulação entre rede e entre profissionais.

Quanto ao desafio de rede, um dos principais problemas surge da dificuldade de se identificar os problemas de saúde mental no âmbito da atenção primária. Mapear os problemas de saúde mental junto às comunidades e compreender as condições associadas a esses problemas constitui uma etapa necessária ao planejamento de ações integrais voltadas à saúde, além de possibilitar intervenções precoces. Assim, para promover integração é apropriado que os serviços de saúde estejam articulados entre si (TARALLI e THOMÉ, 2005a).

Outro desafio que se apresenta na implementação desse modelo é em relação aos profissionais, isso porque, muitos ainda se focam em um serviço de atenção segmentada, e não estabelecem relações com os demais profissionais, impossibilitando assim, o encontro dos núcleos de saberes e fazeres, os quais podem produzir projetos integrados de intervenções em saúde (CAÇAPAVA, COLVERO e MARTINES, 2009b). Nesse sentido, a fomentação de um modelo de atenção biopsicossocial, interdisciplinar e intersetorial tornam possível a articulação dos profissionais e integração de seus fazeres (VINCENTIN, 2006).

Segundo o documento do Ministério da Saúde (2009), a Clínica Ampliada se propõe, enquanto dispositivo, a focar no sujeito como um todo, em sua integridade. Com isso, pretende articular os saberes, manejando e incluindo os diferentes enfoques e disciplinas na atenção integral em saúde. Além disso, o diagnóstico passa a não ser o único dado que define o tratamento e ainda se leva em consideração o que é único e singular em cada indivíduo.

Assim, a função dos trabalhadores de saúde passa a ser, como sugere Winnicott (2005), "cuidar/curar" como extensão do conceito de holding. Então, "cuidar/curar" corresponde à competência dos profissionais da área da saúde em responder às necessidades dos pacientes, isto é, responder às demandas de dependência natural do indivíduo imaturo, que evoca, nas figuras de referência, a tendência a fornecer condições que ampliem o crescimento individual.

\section{Relações como promoção de saúde}

As relações são tema central ao se pensar os modelos de atenção em saúde, afinal, o ser humano se desenvolve em relação. Essas relações 
se dão numa transição entre mundo interno e mundo externo, e ambos constituem-se mutuamente. A qualidade dessas relações dependerá das condições de continência, constância e confiabilidade do ambiente, ou seja, da capacidade do ambiente de suprir as necessidades básicas do bebê, como confiança, segurança, alimentação, higiene e carinho e das características internas, de integração e relações objetais, dos sujeitos envolvidos (WINNICOTT, 1975).

O profissional de saúde mental, especialmente da saúde mental infantil deve ter uma postura acolhedora, escutando o sujeito, suas demandas e singularidades, além de possibilitar o diálogo com os cuidadores, compreendendo a criança em sua totalidade. Assim, ele também passa a ser uma referência de vínculo para a criança. Daí as dificuldades reconhecidas nesse tipo de atividade, posto que as relações constituintes do profissional também estarão presentes. Para promover saúde, o técnico deve, portanto, estar em permanente construção pessoal e profissional. Segundo o documento da Clinica Ampliada (2004), essa convida a uma ampliação do objeto de trabalho para que sujeitos se responsabilizem por sujeitos.

Ademais, percebe-se a importância da relação do paciente infantil com grave sofrimento psíquico com o profissional, visto que esse sofrimento está diretamente envolvido aos aspectos afetivos. Sem amparo, o sujeito tende a se sentir inseguro e com dificuldades para se desenvolver emocionalmente (TARALLI e THOMÉ, 2005).

$\mathrm{Na}$ atenção às crianças, é parte do procedimento terapêutico que o profissional consiga brincar e auxilie o paciente a brincar, pois é na atividade lúdica que se possibilita a manifestação da criatividade e da integração de aspectos cindidos da personalidade. Indubitavelmente, esta capacidade do profissional contribui consideravelmente para a provisão de um ambiente mais saudável.

Diante disso, pode-se pensar que a Clínica Ampliada propõe o cuidado e a atenção aos vínculos e afetos que permeiam as relações, tanto dos usuários para com os profissionais quanto dos profissionais para com os usuários. Por isso, cabe aos profissionais perceberem seus próprios afetos e vínculos e buscar compreendê-los, a fim de tornarem-se propulsores no desenvolvimento dos usuários, favorecendo o processo de amadurecimento. Nesse processo, a equipe de referência é um dispositivo que enriquece o tratamento, isso porque a relação de cada membro da equipe com o usuário e familiares é singular, permitindo que as possibilidades de auxiliar o sujeito doente se ampliem.

Além disso, o sujeito em sofrimento pode ser compreendido como o detentor do saber acerca da sua história e, por conseguinte de sua patologia. Desse modo, o saber popular deve ser considerado na explicação do processo saúde-doença, buscando compreender as representações sociais, tornando possível observar a doença como 
um fenômeno psicossocial, historicamente construido, e como tal, um indicador das ideologias dominantes sobre o adoecer e os doentes em uma determinada sociedade (SPINK, 2007).

A Clínica Ampliada (2004; 2009) expande o "objeto de trabalho", assim o enfoque de qualquer profissional da saúde, indiferente do núcleo profissional ou especialidade, passa a ser a pessoa ou o grupo de pessoas. As doenças e as epidemias deixam de ser o foco do tratamento, e o sujeito detentor da patologia passa a ser visto em sua totalidade. Da mesma forma, é dada a atenção à ideia de clínica compartilhada, na qual, a partir de técnicas relacionais há uma escuta do outro e de si mesmo, e se preconiza uma postura crítica quanto a condutas automatizadas. Isso possibilita uma melhor capacidade de lidar com a expressão de problemas sociais e subjetivos.

Winnicott (1983) enfatiza que o profissional da saúde deve ser capaz de prover um ambiente em que o relacionamento humano seja natural e de livre movimentação. Um dos principais trabalhos nessa relação terapêutica é o apoio humano, ainda que profissional, o qual se torna integrador e se mostra como uma eficiente forma de sustentação. A postura profissional deve dispor de aspectos de confiabilidade, constância, disponibilidade, afetividade e receptividade as demandas e singularidades do sujeito. A vida saudável tem a ver com as várias modalidades de relacionamento objetal e com a forma que o sujeito lida com os objetos externos e internos. Isso é uma questão de pleno usufruto dos vínculos interpessoais. Surge então uma complexa inter-relação entre aquilo que é de dentro e aquilo que é de fora, que se estende ao longo da vida do indivíduo, constituindose na principal relação que ele tem com o mundo.

Nos sujeitos em sofrimento emocional, é promotor de saúde o acesso a um espaço onde, a partir de novas experiências, aqueles possam resignificar um padrão vincular. A doença sempre contém aspectos relacionais e se apresenta como uma forma de comunicação. 0 estabelecimento de novos padrões afetivos, onde surjam vínculos sadios, é essencial no trabalho com transtorno mental grave. Dessa maneira, os sujeitos podem estabelecer novas formas de se comunicar e se relacionar com o mundo (TARALLI e THOMÉ, 2005).

Por isso, é benéfico quando o sujeito em sofrimento compreende o seu adoecimento e estabelece uma correlação entre o que ele sente e a vida, para que o adoecimento possa ser visto de forma agregada à vida do paciente, e não mais de forma isolada onde uma intervenção unilateral do serviço de saúde possa incidir. Dessa forma, uma das diretrizes da Clínica Ampliada passa a ser escutar toda queixa ou relato do usuário, indiferente da relação desta fala com o diagnóstico ou o tratamento.

Logo, a Clínica Ampliada promove um espaço onde toda fala, atuação ou atividade lúdica do paciente pode ser escutada e olhada, a fim de que novos vínculos relacionais possam ser estabelecidos. Nesse 
sentido, é possível pensar que o vínculo apóia e dá significado emocional à comunicação, e que é nesse espaço que se constituem as experiências significativas (WI NNICOTT,1984).

O sentido da intervenção em saúde mental se propõe a ir além da dualidade sujeito/objeto, saúde/doença, individual/social, indagando os tratamentos que não consideram as singularidades. Nessa dinâmica, a Clínica Ampliada no âmbito da saúde mental, busca a promoção de espaços de criação, de invenção de novas práticas, afim de que a construção de novos saberes possibilite novas formas de promover saúde (ALVES e FRANCISCO, 2009).

O objetivo último da atenção ao sujeito acometido de transtorno mental grave, seja adulto ou criança, é promover a caminhada rumo à autonomia, que, conforme a teoria winnicotiana, por vezes, é perdida ou sequer reconhecida. Por autonomia, entende-se o resultado da continuidade da existência que se transforma no senso de existir (WINNICOTT, 1983). Em suma, a Clínica Ampliada se propõe a dar suporte e promover o desenvolvimento no sentido de existência do sujeito e de sua autonomia.

As proposições teóricas apresentadas até aqui reafirmam os norteadores da Clínica Ampliada, no momento em que, ao se propor uma relação entre usuário e profissional, com vínculos claros e bem estabelecidos, o sujeito com transtorno mental grave pode, ao longo do tratamento, restabelecer suas relações com 0 mundo. Por conseguinte, pode-se entender a Clínica Ampliada como promotora de saúde e reintegradora do sujeito em sofrimentos psíquicos graves. A atenção em saúde mental, sustentada pelos preceitos da Clínica Ampliada, parece constituir importantes ambientes que promovam a construção do sujeito em sua autonomia. Isto possibilita que histórias sejam re-significadas e relações restabelecidas, nos aspectos em que aquele ambiente inicial tenha falhado. Assim como Winnicott (1983) ressalta a importância dos cuidados iniciais, também percebemos a relevância dos cuidados primários em saúde, principalmente aqueles representados por serviços inseridos nas comunidades e alinhados às diretrizes da Clinica Ampliada. No entanto, percebemos que tanto os serviços de maior, quanto os de menor complexidade, só adquirem efetivação, de acordo com as diretrizes, se formarem uma rede de atenção comunicante, coesa e bem estabelecida.

Contudo, os obstáculos encontrados no percurso da promoção em saúde são inerentes ao processo de consolidação de um novo paradigma que instaura uma nova forma de atenção à saúde mental infantil. Entre avanços e retrocessos é preciso compreender que este processo é histórico, cultural e social, perpassando gerações e que, são necessárias ações conjuntas muito mais amplas do que o estabelecimento de diretrizes para afirmar os direitos e os valores no cuidado aos sujeitos em sofrimento. 


\section{Referências}

ALVES, E.S.; FRANCISCO, A.L. Ação psicológica em saúde mental: uma abordagem psicossocial. Psicologia Ciência Profissão, vol. 29, n. 4 pp. 768-779, 2009. Disponível em: $<$ http://pepsic. bvsalud.org/scielo. php?pid=S1414-

98932009000400009\&script=sci_arttext> Acesso em: 16 out. 2011. BRASIL. Ministério da Saúde. Clínica ampliada e compartilhada. Secretaria de Atenção à Saúde, Política Nacional de Humanização da Atenção e Gestão do SUS. Brasília, 2009. (Série B. Textos Básicos de Saúde).

BRASIL. Ministério da Saúde. Clínica Ampliada. SecretariaExecutiva Núcleo Técnico da Política Nacional de Humanização. Brasília, 2004.

CAÇAPAVA J.R., COLVERO L.A., MARTINES W.R.V., MACHADO A.L., SILVA A.L.A. E., VARGAS D., OLIVEIRA M. A., BARROS, S. . Trabalho na atenção básica: integralidade do cuidado em saúde mental. Revista Escola De Enfermagem, USP, São Paulo, v. 43, n. 2, p. 1256-1260, 2009. Disponível em: <http://www.scielo.br/pdf/reeusp/v43nspe2/a19v43s2.pdf> Acesso em: 18 nov. 2011.

CARVALHO, E. B.; CECILIO, L. C. O. A regulamentação do setor de saúde suplementar no Brasil: a reconstrução de uma história de disputas. Caderno de Saúde Pública, Rio de Janeiro, v. 23, n. 9, Sept. 2007.

COUTO, M. C. V.; DUARTE, C. S; DELGADO, P. G. G. A saúde mental infantil na saúde pública brasileira: situação atual e desafios. Revista Brasileira Psiquiatria, São Paulo, v. 30, n. 4, 2008. Disponível em: <http://www.scielo.br/pdf/rbp/v30n4/a15v30n4.pdf> Acesso em: 30 out. 2011.

FERRIOLLI S.H.T., MARTURANO E.M., PUNTEL L.P. Contexto familiar e problemas de saúde mental infantil no Programa Saúde da Família. Revista Saúde Pública. Ribeirão Preto, v. 41, n. 2, p. 51-259, $2007 . \quad$ Disponível em: <http://www.scielo.br/pdf/rsp/v41n2/5806.pdf> Acesso em: 13 out. 2011.

ORGANIZAÇÃO Mundial da Saúde - OMS (2001). Relatório mundial da saúde 2001: saúde mental, nova concepção nova esperança. Lisboa: Direção Geral da Saúde, 2002.

ROBERTS R.E., ATTKISSON C.C., ROSENBLATT A. Prevalence of psychopathology among children and adolescents. The American Journal Psychiatry, Houston - USA v.155, n. 6, p.715-25, 1998. Disponível

em:

<http://ajp. psychiatryonline.org/article. aspx?articleid=172855>

Acesso em: 8 nov. 2011. 
SANTOS, M. A. A constituição do mundo psíquico na concepção winnicottiana: uma contribuição à clínica das psicoses. Psicologia Reflexão Crítica, Porto Alegre, v. 12, n. 3, 1999. Disponível em: $<$ http://www.scielo.br/scielo.php?script=sci_arttext\&pid=S0102$79721999000300005 \& \mathrm{lng}=e n \& n r m=i s o>$. Acesso em: 19 abr. 2011.

SEVERO S.B., SEMINOTTI N. Integralidade e transdisciplinaridade em equipes multiprofissionais na saúde coletiva. Ciência \& Saúde Coletiva,Porto Alegre, v. 15, n. 1, 2010. Disponível em: <http://www.scielosp.org/scielo.php?script=sci_pdf\&pid=S1413$81232010000700080 \& \operatorname{lng}=e n \& n r m=i s o \& t \mid n g=p t>$ Acesso em: 28 mai. 2011

SPINK, M. Psicologia social e saúde: práticas, saberes e sentidos. Vozes. Rio de Janeiro. 2007.

TARALLI, I. H. G; THOMÉ, J T. A vivência relacional reconstrutiva e sua ressonância na mente do paciente. Revista Brasileira de Psicoterapia, Porto Alegre vol. 7, n. 1, p. 73-82, 2005. Disponível em: <http://bases.bireme. br/cgi-bin/wxislind.exe/iah/online> Acesso em: 27 out. 2011.

TOLEDO, S. P. R. Integração, Personalização e Realização: A teoria do desenvolvimento emocional de Winnicott. Rio de Janeiro, p. 96, p. 2008. Dissertação (Mestrado em Saúde Coletiva) - Universidade do Estado do Rio de Janeiro. Rio de Janeiro, 2008. Disponível em: <http://www.tesesims.uerj.br/lildbi/docsonline/pdf/toledo_\%20sabrin a.pdf> Acesso em: 20 abr. 2011.

WINNICOTT, D. W. O brincar e a realidade. Rio de Janeiro: Imago. 1975

WINNICOTT, D. W.O ambiente e os processos de maturação: estudos sobre a teoria do desenvolvimento emocional. Porto Alegre: Artes Médicas, 1983.

WINNICOTT, D.W. O jogo do rabisco. In: Explorações Psicanalíticas. Porto Alegre: Artmed, 1984.

WINNICOTT, D. W. Tudo começa em casa. 4a ed.. Martins Fontes, SP, 2005.

VICENTIN M.C.G. Infância e adolescência: uma clínica necessariamente ampliada. Revista Terapia Ocupacional., São Paulo, v. 17, n. 1, p. 10-17, 2006. Disponível em: <http://www.revistasusp. sibi.usp.br/scielo. php?pid=S141591042006000100004\&script=sci_arttext> Acesso em: 18 jul. 2011.

\section{Endereço para correspondência}

Nelcí Regina Angnes

Rua Mal. Floriano Peixoto, 1750, 3o Andar - Sala 321, CEP 97015-372, Santa Maria, RS, Brasil

Endereço eletrônico: nelciagnes@bol.com.br

Caroline Matos Romio 
Nelcí Regina Angnes, Caroline Matos Romio, Gabriela Zuchetto, Hericka Zogbi Jorge Dias Conceitos Winnicottianos integrados na clínica ampliada: um olhar sobre o tratamento do transtorno mental grave na infância

Rua Mal. Floriano Peixoto, 1750, 3o Andar - Sala 321, CEP 97015-372, Santa Maria, RS, Brasil

Endereço eletrônico: carol.matosr@gmail.com

\section{Gabriela Zuchetto}

Endereço: Rua Liberato Salzano, 452, bairro Centro, CEP 96508-740, Cachoeira do Sul, RS, Brasil.

Endereço eletrônico: gabizuchetto@gmail.com

Hericka Zogbi J orge Dias

Rua Orfanotrófio, 555, 2o andar, sala 205. bairro Alto Teresópolis, CEP 90840 440, Porto Alegre, RS, Brasil

Endereço eletrônico: ckzogbi@gmail.com

Recebido em: 14/02/2012

Reformulado em: 15/10/2012

Aceito para publicação em: 08/05/2013

\section{Notas}

* Graduada em psicologia e filosofia pela Universidade Federal de Santa Maria, Rio Grande do Sul.

** Graduada em psicologia, mestranda do Programa de Pós Graduação em Psicologia da Universidade Federal de Santa Maria

*** Graduada em psicologia pela Universidade Federal de Santa Maria, psicóloga na Prefeitura Municipal de Cachoeira do Sul

**** Psicóloga, doutora em psicologia, ex-professora adjunta da Universidade Federal de Santa Maria, Rio Grande do Sul, Brasil.. Coordenadora do projeto PROCONVIVE de 2009 a 2011 (edital PPSUS FAPERGS 02/2009 número de processo 09/0098-2). Professora e coordenadora do Curso de Psicologia do UNIRITTER Porto Alegre. 